\section{Kidney \\ Blood Pressure Research}

\title{
Blood Pressure Seasonality in Hemodialysis Patients from Five European Cities of Different Latitudes
}

\author{
Flore Duranton ${ }^{\mathrm{a}, \mathrm{b}} \quad$ Alfonso Palmac ${ }^{\mathrm{c}}$ Bernd Stegmayr ${ }^{\mathrm{d}} \quad$ Michel Wauthier $^{\mathrm{e}}$ \\ Armando Torres ${ }^{f}$ Àngel Argilés ${ }^{a, b, g}$
}

aRD-Néphrologie, Montpellier, ${ }^{b} \mathrm{BC} 2 \mathrm{M}$, Université Montpellier, Montpellier, France, 'Nephrology Department, Hospital Universitario Virgen Macarena, Sevilla, Spain, dDepartment of Public Health and Clinical Medicine, Umea University, Umea, Sweden, eNephrology Department, Clinique Saint Pierre, Ottignies, Belgium, ${ }^{f}$ Nephrology Department, Hospital Universitario de Canarias, Instituto de Tecnologías Biomédicas, Universidad de La Laguna, Santa Cruz de Tenerife, Spain, 9NDSG, Sète, France

\section{Key Words}

Chronic renal failure $\bullet$ Blood pressure $\bullet$ Weather $\bullet$ Geography $\bullet$ Chronic hemodialysis

\begin{abstract}
Background/Aims: Climate influences the regulation of blood pressure (BP). Our objective was to precisely estimate BP seasonality in hemodialysis (HD) patients from five European cities with marked climate differences. Methods: Stable prevalent HD patients from 5 European facilities (Santa Cruz de Tenerife (Spain), Seville (Spain), Montpellier (France), Ottignies (Belgium), Umea (Sweden)) present over the years 1995-1999 were included in this historical longitudinal observational study. Individual monthly averages of pre-dialysis BP level were computed from all facility BP measurements (>90 000 observations). The association between BP level and location, seasons and meteorological measurements was analyzed by mixed models. Results: 261 patients were included and followed-up for a median duration of 2 years (6903 monthly observations). Pre-dialysis SBP and DBP were minimal in summer (July) and maximal in winter (November and December), and mean changes were respectively $4.2[3.0 ; 5.4]$ and $2.0[1.3 ; 2.7] \mathrm{mmHg}$. Seasonality was confirmed in 4 locations $\left(P_{\text {season }} \leq 0.001\right.$ for SBP and DBP), but not in Umea (both $\mathrm{P}_{\text {season }}>0.05$ ). Seasonal changes in DBP were larger in southern locations $\left(P_{\text {interaction }}=0.02\right)$. BP level was associated with climate parameters: in a positive manner with humidity or rainfall, and inversely with sunshine duration or temperature. The effects of temperature and rainfall on DBP varied with latitude $\left(P_{\text {interaction }}<0.02\right)$ and were greater in southern locations. Conclusion: BP varies with seasons and climate in different European areas and seasonality can be more important in southern locations. These changes in BP deserve attention as they may be responsible for a significant increase in cardiovascular risk which may be preventable.




\section{Kidney Blood Pressure Research}

Duranton et al.: BP Seasonality in HD Patients

\section{Introduction}

Cardiovascular diseases are the leading cause of mortality in the world [1]. Hypertension is a major cardiovascular risk factor, of which control and prevention remain a challenge for modern medicine [2]. Hypertension is often present in $90 \%$ of patients at the moment of transition to dialysis [3]. In chronic kidney disease and end-stage renal disease patients, the control of blood pressure (BP) level is one of the primary therapeutic goals. Despite close BP monitoring and BP-lowering strategies (correction of volume overload, use of BP-lowering medications), elevated BP remains frequent in patients treated with chronic hemodialysis (HD). The determinants of BP level should be studied in the goal of controlling their influences and preventing BP elevation.

In the general population, BP follows cyclic patterns, notably of an annual period which can be described as seasonal cycles [4]. This is also true in HD patients, whose BP has been shown to be higher in winter and lowest in summer [5]. Seasonal changes in BP are likely to induce adverse outcome. Exposure to high BP induces organ damage such as brain damage, heart failure and renal failure [3]. High BP induces mechanical stress on arteries leading to irreversible structural changes including arterial thickening and stiffening, atherosclerosis and vascular calcification. More recently, visit-to-visit BP variability has been described as a cardiovascular risk factor [4], which suggests that transient elevations in BP are likely to trigger the same or other pathways inducing vascular damage. Altogether, this suggests that BP should be maintained at a lower, stable level.

BP seasonality has been reported to have different magnitudes across populations. It varies notably with climate and more specifically with temperature, humidity, rainfall and daylight span [5-7]. Recently, we observed for the first time a link between geographical location, BP level and BP seasonality in HD patients [8] which is in agreement with results from the general population $[9,10]$. Subjects living closer to the poles generally had higher BP and limited BP seasonal variations. In the EURODOPPS study, we analyzed a large population of representative samples from 7 European countries, but longitudinal data collection was performed only every four months, preventing to precisely estimate the magnitude of seasonal changes [8]. The objectives of the present study were to evaluate and quantify the seasonal change in BP in HD patients from 5 European cities located at different latitudes with greater precision. In this goal, we collected and analyzed all BP measurements recorded before dialysis sessions (three times per week) in $261 \mathrm{HD}$ patients followed up to 5 years.

\section{Materials and Methods}

\section{Patients}

This is a retrospective cohort study using longitudinally recorded data produced within the usual practice. Adult patients on chronic hemodialysis present in one of the five selected European facilities in the years 1995-1999 were considered for inclusion. Patients from Seville (latitude of 37.4 N, Spain), Montpellier (43.6 $\mathrm{N}$, France), Ottignies $\left(50.7^{\circ} \mathrm{N}\right.$, Belgium) and Umea $\left(63.8^{\circ} \mathrm{N}\right.$, Sweden) participated in the study up to five years (1995-1999). In Santa Cruz de Tenerife (28.5 $\mathrm{N}$, Spain), patients were seen up to three years (1997-1999). A map is available in Fig. 1. Additional inclusion criteria were a history of 6 months of hemodialysis and a follow-up of 6 months or more. Patients gave oral informed consent to participate in the study.

\section{Data collection}

Age, gender, diabetes, cause of renal failure and dialysis vintage were obtained at study entry. Predialysis $\mathrm{BP}$, pre- and post-dialysis body weight $\left(\mathrm{BW}_{\text {pre }}, \mathrm{BW}_{\text {post }}\right)$ were recorded at each HD session. Blood pressure was measured in the supine position according to local clinical practices. Intra-dialytic weight loss (IDWL) was defined as the difference between pre- and post-dialysis weights expressed as a percentage of post-dialysis weight (IDWL $=100 \times\left[\mathrm{BW}_{\text {pre }}-\mathrm{BW}_{\text {post }}\right] / \mathrm{BW}_{\text {post }}$ ). Monthly means of BP were calculated for 


\section{Kidney Blood Pressure Research}

each patient with 6 or more measurements during the given month. Clinical data were anonymized and centralized.

Climate records from the closest meteorological stations and the moment of the study was obtained from the European Climate Assessment \& Dataset and local meteorological offices [11-13]. The data were summarized as monthly means of average temperature and average humidity and monthly cumulative rainfall height and sunshine duration. Monthly cumulative rainfall height was transformed by the square root to achieve normality. Clinical and meteorological data were merged by location and date.

\section{Exposure}

Patients were considered exposed to temporal, geographical, seasonal and climatic effects. For each patient, the first year of observation was set to 1 and observation dates were then defined as the month and the order of the year. Geographical exposure was defined as the city and the latitude of the city. Seasonal exposure was successively defined by seasons (spring: March, April, May; summer; June, July, August; autumn: September, October, November; winter: December, January, February) or months of the year. Climate exposure was defined by climate data from the actual month and year of observation. Patients were considered climate-sensitive if they had minimal BP in summer and maximal BP in winter or autumn.

\section{Statistical analysis}

We modeled the level of pre-dialytic BP using linear mixed models with random intercepts defined for patients as subjects grouped within facilities, which allowed heterogeneity in covariance matrices across cities. The first model analyzed temporal trends alone and by city. Then, we assessed the independent effects of geographical location (facility or latitude), season (4-level categorical variable) and their interaction (location $\mathrm{x}$ season), adjusting for above-mentioned temporal trends. We similarly analyzed the effect of month (12-level categorical variable). The effects of geographical location (facility or facility latitude), climate exposure and their interaction (location $\mathrm{x}$ climate) adjusting for temporal trends were also analyzed. Subgroup analyses were undertaken to confirm results in specific populations based on location, median age, gender, diabetes, median dialysis vintage, history of hypertension and BP level. The interaction between subgroups and seasonality was tested in a model with seasons as the exposure (subgroup $\mathrm{x}$ season). The size of the seasonal effect in subgroups was estimated from a model with months as the exposure (subgroup $\mathrm{x}$ month).

Statistical analyses were performed using SAS v9.4 (SAS Institute, Cary, NC, USA). All tests were bivariate and P-values $\leq 5 \%$ were considered significant.

\section{Results}

Data from over 90000 dialysis sessions from 5 HD facilities strategically distributed across Europe were obtained (Fig. 1). A total of 261 patients and 6903 monthly observations (mean: 26.4 observations/patient) met inclusion criteria and were further analyzed (Fig. 1). Patients were followed-up for a maximum of five years and a median duration of 2.0 (interquartile range: $1.0 ; 3.2$ ) years. For two facilities, patient characteristics were unavailable due to archive loss or inaccessibility. Overall, glomerulonephrites were the leading cause of renal disease (Table 1). Gender ratios were similar in the different populations. Patients from Seville were slightly younger $\left(\mathrm{P}_{\text {adj }}=0.02 \mathrm{vs}\right.$ Umea $)$ and had been on HD for a longer period $\left(\mathrm{P}_{\text {adj }}<0.001\right.$ vs the other 2 cities).

Across facilities, there were significant differences in pre-dialysis BP level between facilities at baseline $(P=0.004)$. SBP was lower in Santa Cruz, compared to Ottignies $\left(P_{\text {adj }}\right.$ $=0.004)$. A geographical trend was present: on average, SBP was $4.3 \mathrm{mmHg}$ higher for each $10^{\circ}$-increase in latitude (i.e. $1111 \mathrm{~km}$ to the North) with a $95 \%$ confidence interval (CI) of $[2.0 ; 6.6] \mathrm{mmHg} / 10^{\circ} \mathrm{N}, \mathrm{P}<0.001$. There were no clear differences in baseline DBP across cities (all $\mathrm{P}_{\text {adj }}>0.05$ ), but a similar geographical trend was observed, with higher DBP at the poles $\left(+1.7^{\text {adj }}[0.3 ; 3.0] \mathrm{mmHg} / 10^{\circ} \mathrm{N}, \mathrm{P}=0.01\right)$. There was a general trend of decreasing $\mathrm{BP}$ 


\section{Kidney Blood Pressure Research}

Fig. 1. Participant flow diagram and geographical distribution of the five selected facilities across Europe.

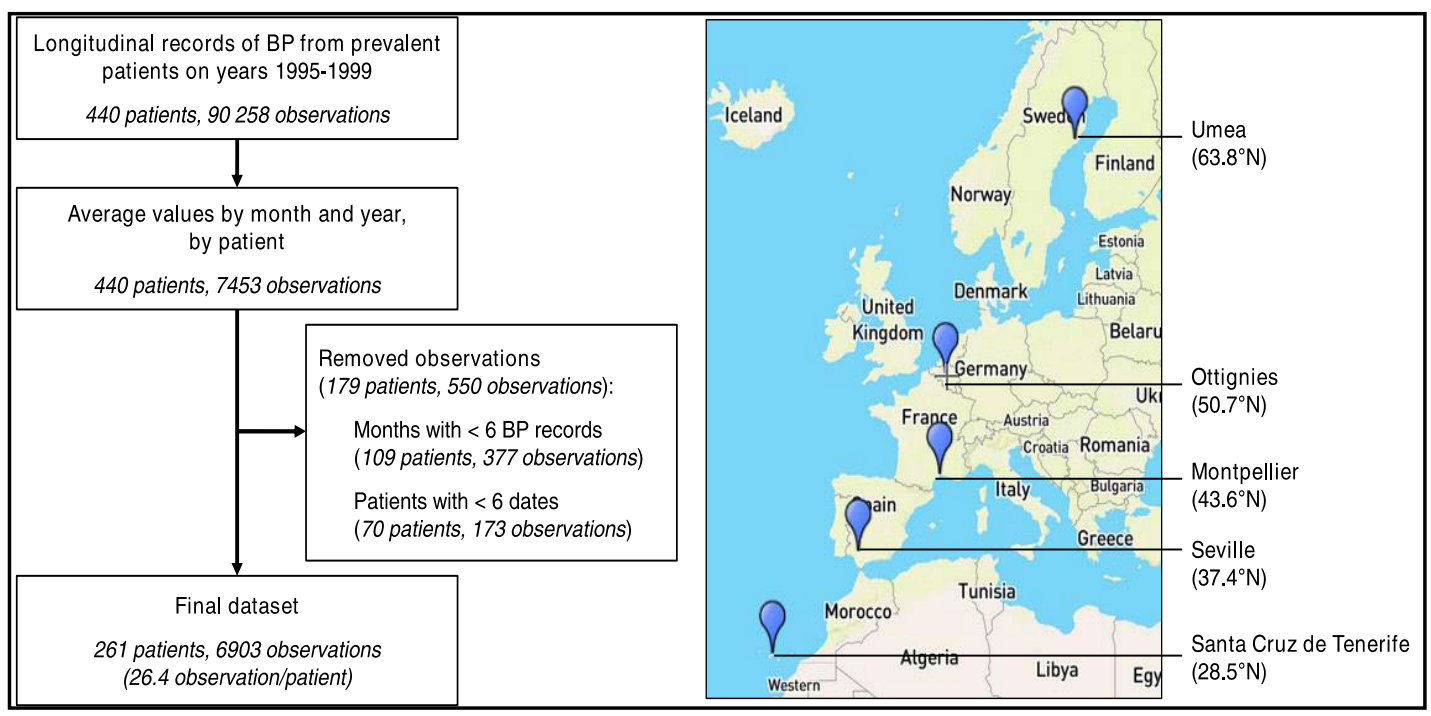

Table 1. Climatic and baseline clinical characteristics of the 5 European facilities.

\begin{tabular}{|c|c|c|c|c|c|}
\hline Characteristics & Santa Cruz & Seville & Montpellier & Ottignies & Umea \\
\hline Number of patients (n) & 69 & 29 & 58 & 88 & 17 \\
\hline \multicolumn{6}{|l|}{ Patients } \\
\hline Age (year) & n.d. & $50.4 \pm 16.7$ & $55.0 \pm 15.6$ & n.d. & $64.3 \pm 14.8$ \\
\hline HD vintage (year) & n.d. & $7(5 ; 14)$ & $3.5(0.8 ; 8.7)$ & n.d. & $1.8(0.9 ; 2.6)$ \\
\hline Female (n (\%)) & n.d. & $16(55 \%)$ & $17(44 \%)$ & $36(43 \%)$ & $7(41 \%)$ \\
\hline Diabetes (n (\%)) & n.d. & $2(7 \%)$ & $5(13 \%)$ & n.d. & $5(31 \%)$ \\
\hline \multicolumn{6}{|l|}{ Renal Disease (n (\%)) } \\
\hline Glomerulonephritis & n.d. & $9(31 \%)$ & $17(44 \%)$ & n.d. & $5(30 \%)$ \\
\hline Genetic disease & n.d. & $6(21 \%)$ & $10(26 \%)$ & n.d. & $2(12 \%)$ \\
\hline Interstitial Nephropathy & n.d. & $5(17 \%)$ & $2(5 \%)$ & n.d. & $4(24 \%)$ \\
\hline Nephrangiosclerosis & n.d. & $3(10 \%)$ & $4(10 \%)$ & n.d. & $0(0 \%)$ \\
\hline Diabetes & n.d. & $2(7 \%)$ & $3(8 \%)$ & n.d. & $4(24 \%)$ \\
\hline Other/unknown & n.d. & $4(14 \%)$ & $3(8 \%)$ & n.d. & $2(12 \%)$ \\
\hline \multicolumn{6}{|l|}{ Pre-dialysis Blood Pressure (mmHg) } \\
\hline Systolic blood pressure & $137 \pm 18$ & $141 \pm 14$ & $147 \pm 18$ & $149 \pm 23$ & $149 \pm 18$ \\
\hline Diastolic blood pressure & $76 \pm 9$ & $81 \pm 7$ & $79 \pm 12$ & $79 \pm 12$ & $83 \pm 16$ \\
\hline Mean arterial pressure & $96 \pm 12$ & $101 \pm 9$ & $102 \pm 13$ & $102 \pm 15$ & $105 \pm 16$ \\
\hline Pulse pressure & $62 \pm 11$ & $60 \pm 11$ & $68 \pm 13$ & $69 \pm 16$ & $66 \pm 12$ \\
\hline \multicolumn{6}{|l|}{ Body weight } \\
\hline Pre-dialysis weight $(\mathrm{kg})$ & $68.4 \pm 14.4$ & $65.8 \pm 10.3$ & $63.7 \pm 13.4$ & $67.6 \pm 16.5$ & $68.7 \pm 12.8$ \\
\hline Post-dialysis weight (kg) & $66.5 \pm 14.1$ & $62.8 \pm 10.2$ & $60.9 \pm 12.8$ & $66.0 \pm 16.4$ & $67.6 \pm 12.7$ \\
\hline Intra-dialytic weight loss (kg) & $1.8 \pm 0.9$ & $3.0 \pm 1.5$ & $2.7 \pm 0.9$ & $1.5 \pm 0.8$ & $2.1 \pm 0.9$ \\
\hline Intra-dialytic weight loss ( $\%$ post-dialysis weight) & $2.8 \pm 1.4$ & $4.9 \pm 2.6$ & $4.5 \pm 1.2$ & $2.4 \pm 1.4$ & $3.3 \pm 1.6$ \\
\hline Facility latitude ( ${ }^{\circ}$ North) & 28.5 & 37.4 & 43.6 & 50.7 & 59.9 \\
\hline \multicolumn{6}{|l|}{ Annual summary of climate } \\
\hline Average temperature $\left({ }^{\circ} \mathrm{C}\right)$ & $19.8 \pm 2.6$ & $19.6 \pm 5.8$ & $15.2 \pm 5.9$ & $10.5 \pm 5.8$ & $3.3 \pm 8.3$ \\
\hline Minimal temperature $\left({ }^{\circ} \mathrm{C}\right)$ & $16.3 \pm 2.3$ & $13.5 \pm 5.0$ & $10.6 \pm 5.6$ & $6.9 \pm 5.1$ & $-0.4 \pm 8.0$ \\
\hline Maximal temperature $\left({ }^{\circ} \mathrm{C}\right)$ & $23.2 \pm 3.0$ & $25.7 \pm 6.7$ & $20.0 \pm 6.2$ & $14.1 \pm 6.6$ & $6.9 \pm 8.7$ \\
\hline Average humidity (\%) & $69.9 \pm 4.0$ & $62.5 \pm 11.8$ & $66.3 \pm 7.1$ & $79.7 \pm 7.1$ & $75.3 \pm 7.1$ \\
\hline Cumulative sun duration (hr) & $231 \pm 55$ & $250 \pm 73$ & $223 \pm 74$ & $131 \pm 70$ & $151 \pm 99$ \\
\hline Cumulative rainfall $(\mathrm{mm})$ & $13(4 ; 49)$ & $23(2 ; 52)$ & $43(15 ; 87)$ & $68(38 ; 88)$ & $52(33 ; 67)$ \\
\hline
\end{tabular}

during follow-up, which was heterogeneous across cities (Fig. 2) and accounted for in all mixed models. 


\section{Kidney Blood Pressure Research}

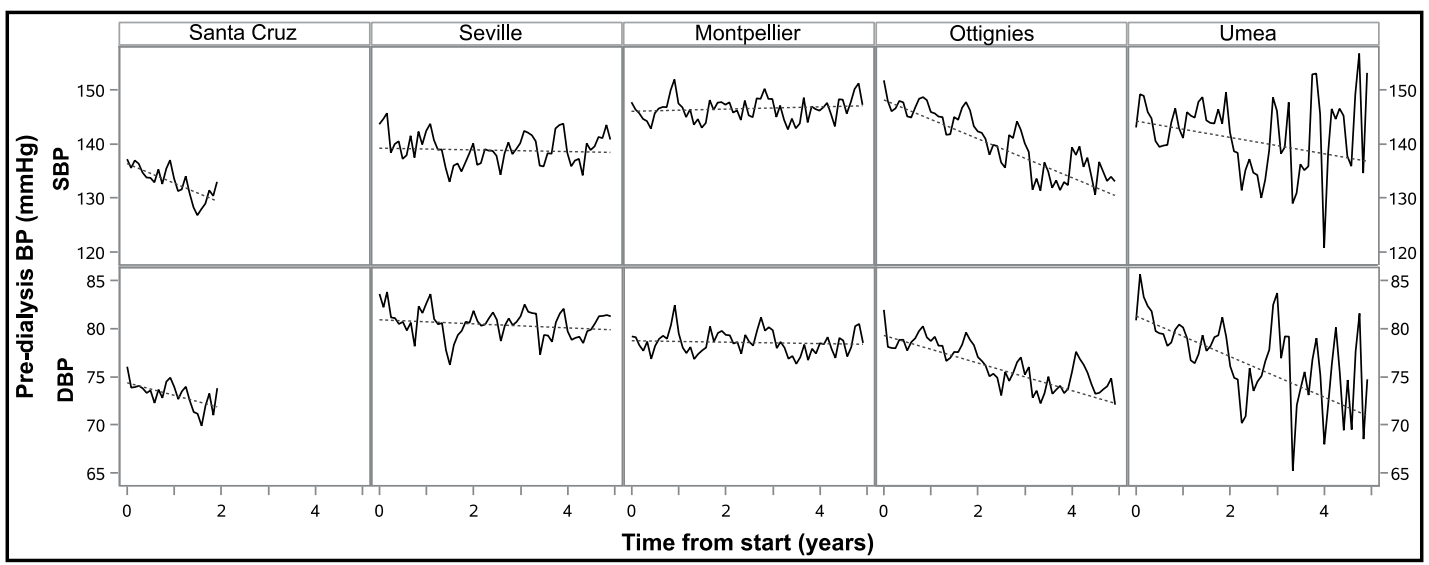

Fig. 2. Monthly means of SBP (upper panel) and DBP (lower panel) by facility during follow-up and respective linear components (dashed lines).

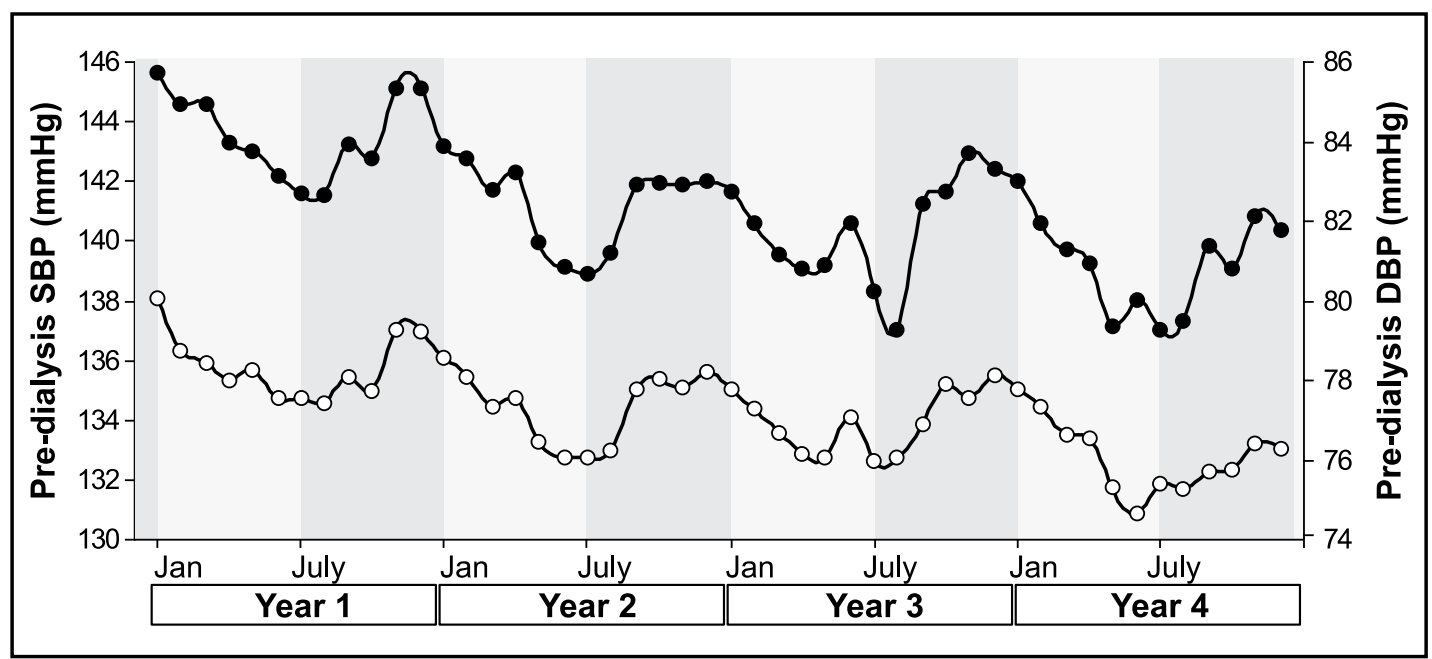

Fig. 3. Evolution of SBP (black dots) and DBP (white dots) over the months during 4 years of follow-up. BP appears to decrease during the first half of the year (light grey) and to increase in the second half (dark gray). Jan: January.

\section{Seasonal change in SBP}

During follow-up, a clear seasonal change in BP was present, with lower values in summer months and higher values in winter months (Fig. 3). The peak-to-peak amplitude of SBP varied between 3.8 and $5.7 \mathrm{mmHg}$ over time. On average, the seasonal change of SBP was $4.7[3.1 ; 6.2] \mathrm{mmHg}\left(\mathrm{P}_{\text {month }}<0.001\right)$, with a maximal SBP level in December and a minimal level in July. Seasonality was observed in all 5 cities (Fig. 4) and subgroup analysis showed it was statistically significant in 4 locations $\left(\mathrm{P}_{\text {season }} \leq 0.001\right)$ but not in Umea $\left(\mathrm{P}_{\text {season }}\right.$ $=0.07)$. The peak-to-peak amplitude of change in monthly SBP was $6.1[3.1 ; 9.1] \mathrm{mmHg}$ in Santa Cruz, 4.6 [1.8 ; 7.5] mmHg in Seville, 5.3 [3.1 ; 7.5] mmHg in Montpellier, 4.4 [2.1; 6.7] $\mathrm{mmHg}$ in Ottignies, and $7.2[1.4 ; 13.1] \mathrm{mmHg}$ in Umea. Analyzing the change by season resulted in a smaller estimate of SBP seasonality (change from summer to winter: 3.1 [2.2 ; 4.0 $\mathrm{mmHg}$ ) and confirmed the presence of an interaction between seasons and facilities $\left(\mathrm{P}_{\text {interaction }}=0.03\right)$. There was a shift in the seasonal peaks in Montpellier and Ottignies, where maximal SBP was observed in spring, and minimal levels in autumn (Table 2). However, there was no clear relationship between latitude and estimates of seasonal change $\left(\mathrm{P}_{\text {interaction }}=0.1\right)$.

Patients from different facilities were exposed to different climates. Southern places were globally warmer and sunnier, with a more stable climate along the year (Table 1). 


\section{Kidney Blood Pressure Research}

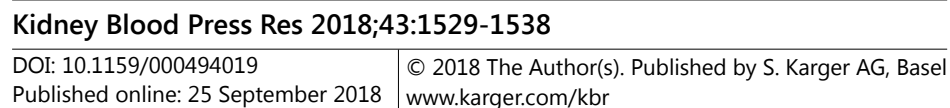

Duranton et al.: BP Seasonality in HD Patients

Table 2. Estimates of pre-hemodialysis blood pressure level by city and season, and of the Winter-Summer difference. Data are expressed as mean \pm standard error of the mean or estimate and $95 \%$ confidence interval

\begin{tabular}{lccccc}
\hline Blood pressure (mmHg) & Santa Cruz & Seville & Montpellier & Ottignies & Umea \\
\hline Systolic blood pressure (SBP) & & & & & \\
$\quad$ Winter & $131.8 \pm 2.3$ & $140.4 \pm 2.7$ & $147.4 \pm 2.0$ & $143.3 \pm 2.0$ & $143.2 \pm 3.7$ \\
Spring & $131.0 \pm 2.4$ & $139.3 \pm 2.7$ & $145.1 \pm 2.0$ & $140.9 \pm 2.0$ & $142.8 \pm 3.7$ \\
Summer & $128.7 \pm 2.3$ & $137.0 \pm 2.7$ & $145.0 \pm 2.0$ & $141.0 \pm 2.0$ & $138.9 \pm 3.7$ \\
Autumn & $131.2 \pm 2.3$ & $139.2 \pm 2.7$ & $147.9 \pm 2.0$ & $144.4 \pm 2.0$ & $142.5 \pm 3.7$ \\
$\quad$ Winter-Summer difference & $3.1[1.4 ; 4.8]$ & $3.4[1.8 ; 5.1]$ & $2.3[1.0 ; 3.6]$ & $2.3[0.9 ; 3.6]$ & $4.3[1.1 ; 7.5]$ \\
Diastolic blood pressure (DBP) & & & & \\
$\quad$ Winter & $73.2 \pm 1.1$ & $81.7 \pm 1.3$ & $79.2 \pm 1.1$ & $77.6 \pm 1.0$ & $79.3 \pm 3.3$ \\
Spring & $72.5 \pm 1.1$ & $80.9 \pm 1.3$ & $77.9 \pm 1.1$ & $76.3 \pm 1.0$ & $77.5 \pm 3.3$ \\
Summer & $71.3 \pm 1.1$ & $79.3 \pm 1.3$ & $78.0 \pm 1.1$ & $76.3 \pm 1.0$ & $77.1 \pm 3.3$ \\
Autumn & $72.5 \pm 1.1$ & $80.5 \pm 1.3$ & $79.4 \pm 1.1$ & $77.9 \pm 1.0$ & $78.3 \pm 3.3$ \\
Winter-Summer difference & $1.9[1.0 ; 2.8]$ & $2.3[1.4 ; 3.2]$ & $1.2[0.5 ; 1.9]$ & $1.3[0.6 ; 2.0]$ & $2.2[0.5 ; 3.9]$ \\
\hline
\end{tabular}

Table 3. Association of systolic (SBP) and diastolic (DBP) blood pressure level with seasons or climate obtained from different models. All models are adjusted on latitude, time and time $\times$ city. Climate and seasonal effects are reported at a latitude of $45^{\circ}$ (average latitude across the 5 cities). Significant interactions mean that the effect of climate or season varies with latitude. To calculate the effect size of climate at a latitude of $55^{\circ}\left(10^{\circ}\right.$-increase in latitude), one should add the effect sizes of climate and of the interaction. Non-significant interactions were removed from models

\begin{tabular}{lcccc}
\hline Model and effects (unit of change) & $\begin{array}{c}\text { SBP } \\
\text { effect size and 95\% CI }\end{array}$ & P-value & $\begin{array}{c}\text { DBP } \\
\text { effect size and 95\% CI }\end{array}$ & P-value \\
\hline $\begin{array}{l}\text { Seasons } \\
\quad \text { Seasons }(\Delta \text { Win-Sum) }\end{array}$ & $2.8[2.0 ; 3.5]$ & $<0.001$ & $1.6[1.2 ; 2.0]$ & 0.01 \\
$\quad$ Seasons $\left(\Delta\right.$ Win-Sum) $\times$ Latitude $\left(10^{\circ}\right)$ & - & - & $-0.2[-0.6 ; 0.2]$ & 0.02 \\
$\begin{array}{l}\text { Months } \\
\quad \text { Months }(\Delta \text { Nov-Jul) }\end{array}$ & $4.2[3.0 ; 5.4]$ & $<0.001$ & $1.9[1.3 ; 2.6]$ & $<0.001$ \\
$\begin{array}{l}\text { Cumulative sunshine duration } \\
\quad \text { Sunshine }(85 \mathrm{hr})\end{array}$ & $-1.4[-1.7 ;-1.1]$ & $<0.001$ & $-0.8[-0.9 ;-0.6]$ & $<0.001$ \\
$\begin{array}{l}\text { Average temperature } \\
\quad \text { Temperature }\left(7^{\circ} \mathrm{C}\right)\end{array}$ & $-1.3[-1.6 ;-1.0]$ & $<0.001$ & $-0.7[-0.9 ;-0.6]$ & $<0.001$ \\
$\quad$ Temperature $\left(7^{\circ} \mathrm{C}\right) \times$ Latitude $\left(10^{\circ}\right)$ & - & - & $0.2[0.03 ; 0.5]$ & 0.02 \\
$\begin{array}{l}\text { Average humidity } \\
\quad \text { Humidity }(10 \%)\end{array}$ & $1.3[0.9 ; 1.6]$ & $<0.001$ & $0.7[0.6 ; 0.9]$ & $<0.001$ \\
$\begin{array}{l}\text { Cumulative rainfall } \\
\quad \text { Rainfall }(44 \mathrm{~mm}) \\
\text { Rainfall }(44 \mathrm{~mm}) \times \text { Latitude }\left(10^{\circ}\right)\end{array}$ & $0.6[0.3 ; 0.9]$ & $<0.001$ & $0.2[0.1 ; 0.4]$ & $<0.001$ \\
& - & - & $-0.3[-0.5 ;-0.1]$ & $<0.001$ \\
\hline
\end{tabular}

In all patients, SBP decreased with outdoor temperatures and sunshine duration, while it increased with humidity and rainfall (all $\mathrm{P}<0.001$, Table 3). The association between climatic parameters and SBP level was not modified by latitude $\left(\mathrm{P}_{\text {interaction }}>0.1\right)$. This means that when exposed to the same increase in temperature, SBP changed of a similar absolute level in any location (i.e. $-1.3 \mathrm{mmHg} / 7^{\circ} \mathrm{C}$, Table 3 ).

There were indications of interactions between SBP seasonal change and groups of age, diabetes and blood pressure level. Patients with diabetes had higher SBP $(9.9[1.1 ; 18.7]$ $\mathrm{mmHg}, \mathrm{P}=0.03)$ and larger seasonal changes in SBP $(10.3[4.6 ; 16.0]$ vs $4.1[2.1 ; 6.1]$ $\mathrm{mmHg} ; \mathrm{P}_{\text {diabetes } \times \text { season }}=0.02$ ). Seasonality tended to be greater in patients aged 60 and older (difference in extreme months: $6.5[4.0 ; 9.0]$ vs $3.2[0.4 ; 5.9] \mathrm{mmHg} ; \mathrm{P}_{\text {age group } \times \text { season }}=0.06$ ) and in patients with lower BP (DBP below $80 \mathrm{mmHg}: 3.8[2.5 ; 5.2]$ vs $1.5[-0.2 ; 3.2] \mathrm{mmHg}$; $\mathrm{P}_{\mathrm{BP} \text { group } \times \text { season }}=0.05$ ).

There were 115 patients (44\%) whose SBP was minimal in summer, which is unlikely to be explained by chance only $(\mathrm{P}<0.001)$. The maximal values were more frequently observed in winter (77 patients, 30\%) and autumn (85 patients, 33\%), $\mathrm{P}<0.001$. Out of 12 


\section{Kidney Blood Pressure Research}

Fig. 4. Change in monthly estimations of pre-dialysis SBP (upper panel) and DBP (lower panel) along the yearly cycle, by facility. Estimates were adjusted for longitudinal trends. The difference between the estimate and the facility average are displayed.

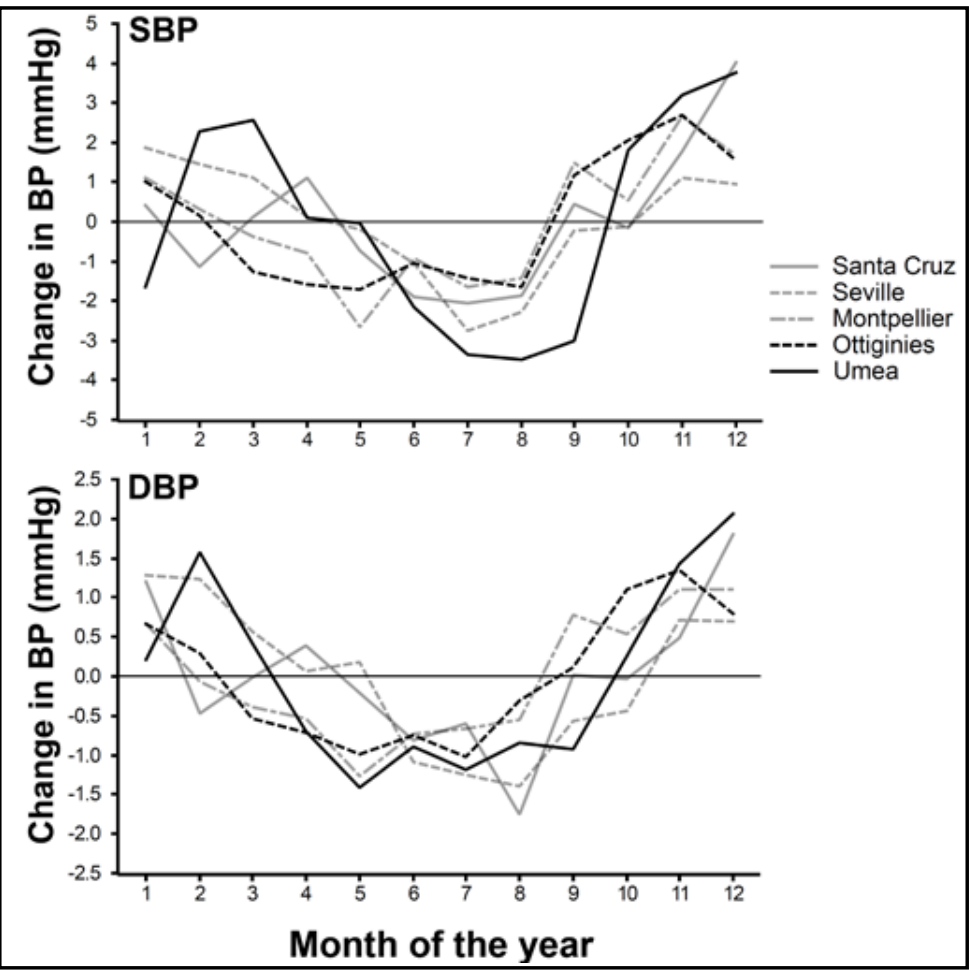

possibilities, the combination of a summer minimum with a winter or autumn peak were the most frequent (respectively $46(18 \%)$ and $42(16 \%)$ patients). The mean seasonal change was $11.2[9.6 ; 12.9] \mathrm{mmHg}$ in these 88 "climate-sensitive" patients.

\section{Seasonal change in $D B P$}

Over time, DBP varied with annual cycles of peak-to-peak amplitudes as high as 4.6 $\mathrm{mmHg}$, as observed during the first year (Fig. 2). Extreme DBP values occurred in July (minimum) and December (maximum) with an average difference of $2.0[1.3 ; 2.7] \mathrm{mmHg}$, which was comparable across locations (Fig. 4). The seasonal change was maximal from summer to winter $\left(1.8[1.3 ; 2.3] \mathrm{mmHg}, \mathrm{P}_{\text {season }}<0.001\right)$ and there was a significant interaction with facilities $\left(\mathrm{P}_{\text {interaction }}=0.02\right)$ or latitude $\left(\mathrm{P}_{\text {interaction }}=0.02\right.$, Table 3$)$. The effect of season was significant in 4 locations $\left(\mathrm{P}_{\text {season }}<0.001\right)$, not in Umea $\left(\mathrm{P}_{\text {season }}=0.15\right)$. In Montpellier and Ottignies, the highest and lowest DBP occurred in autumn and spring (see Table 2). The level of DBP was lower when sunshine exposure and outdoor temperature increased, while it was lower when humidity and rainfall decreased (all $\mathrm{P}<0.001$, Table 3). There were significant interactions of latitude with outdoor temperature and rainfall, both displayed larger effects in the South (Table 3).

\section{Discussion}

This study shows that BP seasonality can be observed in a mixed group of HD patients from different locations in Europe. The average intra-individual change from summer (July) to winter (November) was $4 \mathrm{mmHg}$ and $2 \mathrm{mmHg}$ for pre-dialysis SBP and DBP respectively. It is now established that BP decreases of a significant amount in summer, although this may not occur in all populations, nor all locations $[5,6,8,14,15]$. The magnitude of seasonal cycles was greater in older, normotensive or diabetic HD patients. In the latter and in patients identified as climate-sensitive, the peak-to-peak amplitude of SBP seasonal pattern exceeded $10 \mathrm{mmHg}$. Such changes in BP are likely to have substantial clinical consequences. Indeed, 


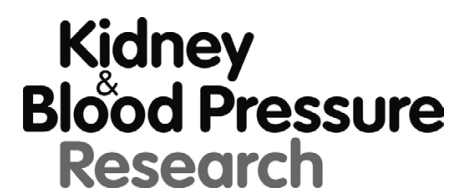

Kidney Blood Press Res 2018;43:1529-1538

\begin{tabular}{|l|l|l|}
\hline DOI: $10.1159 / 000494019$ & C 2018 The Author(s). Published by S. Karger AG, Basel \\
\hline
\end{tabular} Published online: 25 September 2018 www.karger.com/kbr

both elevated and reduced BP are associated with the risk of cardiovascular mortality in HD patients [16-18]. Elevated BP is responsible for long-term organ damage, notably cardiac dysfunction, which eventually leads to low BP and adverse events [3].

Climate is expected to be a major cause of seasonal patterns. We observed that increasing outdoor temperatures and longer sunshine duration were consistently associated with lower pre-dialysis BP, while humidity and rainfall were associated with increasing BP. Comfortingly, these results confirm those of our recent study which had similar objectives but different methods [8]. The influence of climate may occur through direct effect such as temperature-induced vasoconstriction and sweating [19]. In addition, indirect effects may occur such as UV-related vitamin D or nitric oxide synthesis, exercise-related perspiration and changes in dietary and water intake $[19,20]$. Hydration status, a major determinant of BP level in HD patients, is also affected by external temperature and humidity $[6,7,14]$. Increasing temperature triggers sweating to evacuate body heat, but this is limited in humid environments possibly due to skin saturation in water [21]. This is consistent with the direct association between humidity and BP level that we observed in the present and in earlier studies $[7,8]$. While the seasonal pattern was present and similar in the different facilities, it could not be clearly confirmed in Umea. This is likely due to the limited sample size from this location and a corresponding loss of sensitivity. Surprisingly, patients from Umea consistently presented a drop in BP in January, which may have additionally prevented to observe a seasonal effect. This drop could be related to the holiday seasons and the consumption of salty festive food (herring, ham) urging fluid intake and lowering BP in patients with inadequate heart function.

The influence of seasonal effect should be taken into account when forecasting BP changes and prescribing treatments modulating BP level. Adapting antihypertensive medications and dialysis therapies to BP seasonality could help avoid dramatic BP rises in winter or reduction in summer. In older individuals, a $5 \mathrm{mmHg}$-decrease in SBP is associated with a $15 \%$ reduction in cardiovascular mortality [22], and the successful stabilization of $\mathrm{BP}$ over time could reduce the risk by $20 \%$ [23]. In normotensive or diabetic patients, the decrease in BP observed in summer could also lead to episodes of symptomatic hypotension and have detrimental consequences [24]. In this context, taking BP seasonality into account in predictions and prescriptions could also have a significant beneficial impact.

This study is based on BP measurements that were repeated at a high frequency. On average, each patient had 26 monthly BP observations (2.2 years), each one being the summary of around $11 \mathrm{BP}$ measurements. This specific design allowed estimating precisely the within-patient change in BP, with regards to the monthly, seasonal and climatic exposure. In the EURODOPPS study, we analyzed a small number of BP measurements in a large population across Europe, which provided different yet consistent results [8]. In the present article, we were able to observe greater changes of BP (up to $6 \mathrm{mmHg}$ of SBP) and we observed interactions between facilities and seasons or climate, which were partly reproduced when analyzing latitude as the geographical exposure. Using this approach, we reported estimates that were at least twice as high as in our previous study [8]. Finally, we confirmed the presence of a geographical trend in BP, which is lower in HD patients living in southern locations [8]. However, due to the limited number of patients and locations, this study was less adapted to the evaluation of geographical trends of either BP level or BP seasonality than the EURODOPPS study.

We observed a time trend of decreasing BP over the study period which could not be explained by changes in climate. This could reflect an improvement in patients profile or in contrast the expression of cardiac impairment. This could also indicate the presence of a selection bias, due to the fact that patients with worse health profiles are more likely to end their participation to the study due to adverse events. In addition, the present study included a limited sample of prevalent patients from each facility and it is consequently unlikely that these samples were representative of the local HD population, in contrast with the EURODOPPS study [8]. However, because we obtained many longitudinal records for each 


\section{Kidney Blood Pressure Research}

patient, our study is well designed to assess the longitudinal changes in BP and the effect of climate on intra-individual change in blood pressure. The data were collected some time ago and one may think that patients do not reflect current HD patients. However, results were confirmed across groups of patients with different characteristics (age, diabetes). Hence, we believe that the results we present are relevant to current HD populations. Comfortingly, the results from our recent EURODOPPS study are very much in line with the present article.

\section{Conclusion}

We showed the presence of a geographical gradient in BP in HD patients and the presence of seasonal changes in different European locations. In addition to the difference in climate itself, the influence of climate also varied with location. These effects should be considered when evaluating and treating BP. BP seasonal changes affect the cardiovascular risk as well as its evaluation, which may be biased by the time of BP measurement, i.e. in summer when BP is generally lower. The use of BP medications should also be adapted to seasons or based on regular BP monitoring, if not the case. A tight monitoring of BP, with regards to seasonality, and seasonally-adapted therapeutic strategies could improve BP control and limit cardiovascular risks.

\section{Disclosure Statement}

The authors declare that no conflict of interest exists.

\section{References}

-1 Lozano R, Naghavi M, Foreman K, Lim S, Shibuya K, Aboyans V, Abraham J, Adair T, Aggarwal R, Ahn SY,

Alvarado M, Anderson HR; Anderson LM, Andrews KG, Atkinson C, Baddour LM, Barker-Collo S, Bartels DH, Bell ML, Benjamin EJ, et al.: Global and regional mortality from 235 causes of death for 20 age groups in 1990 and 2010: a systematic analysis for the Global Burden of Disease Study 2010. Lancet 2012;380:20952128.

- Kotchen TA, Cowley AW, Liang M: Ushering Hypertension Into a New Era of Precision Medicine. JAMA 2016;315:343.

3 Ok E, Asci G, Chazot C, Ozkahya M, Mees EJD: Controversies and problems of volume control and hypertension in haemodialysis. The Lancet 2016;388:285-293.

4 Parati G, Ochoa JE, Lombardi C, Bilo G: Assessment and management of blood-pressure variability. Nat Rev Cardiol 2013;10:143-155.

5 Argilés A, Mourad G, Mion C: Seasonal changes in blood pressure in patients with end-stage renal disease treated with hemodialysis. N Engl J Med 1998;339:1364-1370.

6 Spósito M, Nieto FJ, Ventura JE: Seasonal variations of blood pressure and overhydration in patients on chronic hemodialysis. Am J Kidney Dis 2000;35:812-818.

7 Argilés A, Lorho R, Servel M-F, Chong G, Kerr PG, Mourad G: Seasonal modifications in blood pressure are mainly related to interdialytic body weight gain in dialysis patients. Kidney Int 2004;65:1795-1801.

-8 Duranton F, Kramer A, Szwarc I, Bieber B, Gayrard N, Jover B, Vetromile F, Massy ZA, Combe C, Tentori F, Jager KJ, Servel MF, Argilés À: Geographical Variations in Blood Pressure Level and Seasonality in Hemodialysis Patients. Hypertension 2018;71:289-296.

-9 Barnett AG, Sans S, Salomaa V, Kuulasmaa K, Dobson AJ, WHO MONICA Project: The effect of temperature on systolic blood pressure. Blood Press Monit 2007;12:195-203.

10 Cabrera SE, Mindell JS, Toledo M, Alvo M, Ferro CJ: Associations of Blood Pressure With Geographical Latitude, Solar Radiation, and Ambient Temperature: Results From the Chilean Health Survey, 2009-2010. Am J Epidemiol 2016;183:1071-1073. 


\section{Kidney \\ Blood Pressure Research}

11 Météo France: Données Publiques de Météo-France - Données mensuelles 2015. URL: https:// donneespubliques.meteofrance.fr/?fond=produit\&id_produit=114\&id_rubrique=37.

12 Météo Belgique: Météo en Belgique: Archive des stations 2015. URL: http://www.meteobelgique.be/ premium/observation/archive-des-stations.html.

13 European Climate Assessment \& Dataset: Indices data 2015. URL: http://www.ecad.eu/download/ millennium/millennium.php.

14 Broers NJH, Usvyat LA, Marcelli D, Bayh I, Scatizzi L, Canaud B, van der Sande FM, Kotanko P, Moissl U, Kooman JP, on behalf the MONitoring Dialysis Outcomes (MONDO) Consortium: Season affects body composition and estimation of fluid overload in haemodialysis patients: variations in body composition; a survey from the European MONDO database. Nephrol Dial Transplant 2014;30:676-681.

-15 Guinsburg AM, Usvyat LA, Etter M, Xu X, Thijssen S, Marcelli D, Canaud B, Marelli C, Barth C, Wang Y, Carioni P, van der Sande FM, Kotanko P, Kooman JP, Monitoring Dialysis Outcomes (MONDO) consortium: Seasonal variations in mortality and clinical indicators in international hemodialysis populations from the MONDO registry. BMC Nephrol 2015;16:139.

-16 Zager PG, Nikolic J, Brown RH, Campbell MA, Hunt WC, Peterson D, Van Stone J, Levey A, Meyer KB, Klag MJ, Johnson HK, Clark E, Sadler JH, Teredesai P: “U” curve association of blood pressure and mortality in hemodialysis patients. Kidney Int 1998;54:561-569.

17 Robinson BM, Tong L, Zhang J, Wolfe RA, Goodkin DA, Greenwood RN, Kerr PG, Morgenstern H, Li Y, Pisoni RL, Saran R, Tentori F; Akizawa T, Fukuhara S, Port FK: Blood pressure levels and mortality risk among hemodialysis patients in the Dialysis Outcomes and Practice Patterns Study. Kidney Int 2012;82:570-580.

-18 Duranton F, Duny Y, Szwarc I, Deleuze S, Rouanet C, Selcer I, Maurice F, Rivory JP, Servel MF, Jover B, Brunet P, Daurès JP, Árgiles À: Early changes in body weight and blood pressure are associated with mortality in incident dialysis patients. Clin Kidney J 2016;9:287-294.

19 Rostand SG: Ultraviolet Light May Contribute to Geographic and Racial Blood Pressure Differences. Hypertension 1997;30:150-156.

20 Johnson RS, Titze J, Weller R: Cutaneous control of blood pressure. Curr Opin Nephrol Hypertens 2016;25:11-15.

21 Gisolfi CV, Wilson NC, Claxton B: Work-heat tolerance of distance runners. Ann N Y Acad Sci 1977;301:139150.

22 Lewington S, Clarke R, Qizilbash N, Peto R, Collins R, Prospective Studies Collaboration: Age-specific relevance of usual blood pressure to vascular mortality: a meta-analysis of individual data for one million adults in 61 prospective studies. Lancet Lond Engl 2002;360:1903-1913.

23 Stevens SL, Wood S, Koshiaris C, Law K, Glasziou P, Stevens RJ, McManus RJ: Blood pressure variability and cardiovascular disease: systematic review and meta-analysis. BMJ 2016;i4098.

24 Hoffmann B, Luttmann-Gibson H, Cohen A, Zanobetti A, de Souza C, Foley C, Suh HH, Coull BA, Schwartz J, Mittleman M, Stone P, Horton E, Gold DR: Opposing effects of particle pollution, ozone, and ambient temperature on arterial blood pressure. Environ Health Perspect 2012;120:241-246. 